\title{
Kesiapan Mahasiswa Menghadapi Pembelajaran Daring di Masa Pandemi Covid - 19
}

\author{
Ni Luh Putu Nina Sriwarthini' ${ }^{1}$, Muhammad Syazali dan Deni Sutisna
}

Universitas Mataram

\begin{abstract}
The education sector is one of the many sectors that most feel the impact of changes due to the covid-19 pandemic. Starting from early childhood education level to higher education level has now started to try to adapt to the covid-19 pandemic situation. The purpose of this research is to get information on student readiness, especially PGSD study program in facing online learning during the covid-19 pandemic. Student readiness is reviewed from 3 aspects, namely, readiness in terms of facilities and infrastructure owned, readiness in terms of the ability to use media / online learning platforms, and readiness in facing obstacles that will arise when online learning is implemented. The subjects of this study were students of PGSD FKIP Mataram University semesters 1, 3, and 5. This research is a qualitative descriptive research. Data collection is done by disseminating questionnaires and interviews to students in each semester. The data obtained is then analyzed using miles and huberman analysis model (Analysis Interactive Model). The results of the research showed that most PGSD students are ready to carry out online learning during the covid-19 pandemic, reviewed in terms of readiness in terms of facilities and infrastructure owned, readiness in terms of the ability to use online media / learning platforms, and readiness in facing obstacles that will arise when online learning is implemented
\end{abstract}

Keywords : Readiness, Covid-19, Online learning

\begin{abstract}
Abstrak
Sektor pendidikan adalah salah satu sektor dari sekian banyak sektor yang paling merasakan dampak perubahan akibat pandemi covid - 19 ini. Mulai dari jenjang pendidikan anak usia dini hingga jenjang pendidikan tinggi kini telah mulai mencoba beradaptasi dengan keadaan pandemi covid - 19 ini. Tujuan penelitian ini yaitu untuk mendapatkan informasi kesiapan mahasiswa khususnya prodi PGSD dalam menghadapi pembelajaran daring di masa pandemi covid-19. Kesiapan mahasiswa ini ditinjau dari 3 aspek yaitu, kesiapan dari segi sarana dan prasarana yang dimiliki, kesiapan dari segi kemampuan penggunaan media / platform pembelajaran daring, dan kesiapan dalam menghadapi kendala yang akan muncul pada saat pembelajaran daring dilaksanakan. Subjek penelitian ini yaitu mahasiswa PGSD FKIP Universitas Mataram semester 1. Penelitian ini merupakan penelitian deskriptif kualitatif. Pengumpulan data dilakukan dengan cara penyebaran angket dan wawancara pada mahasiswa semester 1. Data yang diperoleh kemudian dianalisis menggunakan model analisis Miles dan Huberman (Analysis Interactive Model). Hasil penelitian yang dilakukan menunjukkan bahwa sebagian besar mahasiswa PGSD semester 1 telah siap melaksanakan pembelajaran secara daring dimasa pandemi covid - 19 ini, ditinjau dari kesiapan dari segi sarana dan prasarana yang
\end{abstract}

1'ninasriwarthini@unram.ac.id 
dimiliki, kesiapan dari segi kemampuan penggunaan media / platform pembelajaran daring, dan kesiapan dalam menghadapi kendala yang akan muncul pada saat pembelajaran daring dilaksanakan

Kata Kunci : Kesiapan, Covid - 19, Pembelajaran Daring

\section{Pendahuluan}

Pembelajaran dalam jaringan (daring) dapat menjangkau kelompok target yang luas, sehingga pembelajaran dapat diselenggarakan dimana saja serta diikuti secara gratis maupun berbayar (Bilfaqih dan Qomarudin, 2015). Pembelajaran daring atau penerapan e-learning dalam pendidikan tinggi telah menjadi solusi praktis untuk masalah yang dihadapi di tengah kondisi pandemik covid - 19 (Nichols dan McLachlan, 2006). Agar pelaksanaan pembelajaran daring dapat berjalan dengan efektif, diperlukan persiapan seluruh stakeholder pendidikan tinggi. Tujuan dilakukannya pembelajaran daring adalah: 1) Memastikan pemenuhan hak anak untuk mendapatkan layanan pendidikan selama pandemik covid-19, 2) Melindungi warga negara satuan pendidikan dan dampak buruk pandemik covid19, 3) Mencegah penyebaran dan penularan covid-19 di satuan pendidikan dan, 4) Memastikan pemenuhan dukungan psikososial bagi pendidik, peserta didik dan orang tua/wali.

Pembelajaran secara daring ini merupakan salah satu inovasi untuk menjawab tantangan akan ketersediaan sumber belajar yang variatif. Keberhasilan dari suatu model ataupun media pembelajaran tergantung dari karakteristik peserta didiknya. Sebagai mana yang diungkapkan oleh Nakayama bahwa dari semua literatur dalam e-learning mengindikasikan bahwa tidak semua peserta didik akan sukses dalam pembelajaran online. Ini dikarenakan faktor lingkungan belajar dan karakteristik peserta didik (Nakayama M, dan Yamamoto H, 2007). Kelebihan pembelajaran daring diantaranya dapat memberikan metode pembelajaran yang lebih bervariatif dengan adanya umpan balik, menggabungkan kegiatan belajar terbimbing dengan belajar mandiri, personalisasi pembelajaran berdasarkan kebutuhan peserta didik yang menggunakan simulasi dan permainan (Ghirardini, 2011). 
Terdapat beberapa model yang dapat digunakan dalam mengukur kesiapan dalam pelaksanaan pembelajaran daring, salah satunya yang digunakan oleh Aydin dan Tasci (2005). Mereka mengemukakan bahwa terdapat 4 faktor utama yang memengaruhi pembelajaran daring yaitu faktor teknologi, inovasi, manusia dan pengembangan diri. Hasil penelitian dari Setiaji dan Dinata (2020) yang menganalisis kesiapan mahasiswa jurusan Pendidikan fisika UNY menggunakan $e_{-}$ learning dalam situasi pandemik covid - 29, mengemukakan bahwa mahasiswa jurusan Pendidikan fisika UNY termasuk dalam kategori siap. Indikator yang dianalisis yaitu keterampilan menggunakan smartphone, komputer atau laptop, pemahaman terhadap e-learning, kesiapan menerima materi pembelajaran, dan sikap positif mahasiswa terhadap teknologi komputer dan internet.

Faslah dan Santoso (2017) juga melakukan penelitian penggunaan analisis kesiapan implementasi e-learning pada Politeknik Hasnur yang menunjukkan kategori siap. Terdapat beberapa peningkatan yang perlu dilakukan dari segi teknologi, inovasi serta peningkatan pengembangan diri dari dosen maupun dari mahasiswa. Peneliti juga menyarankan adanya pelatihan terkait dengan pembelajaran e-learning pada mahasiswa maupun dosen untuk meningkatkan tingkat kesiapan penggunaan e-learning. Pada jenjang SMA, analisis kesiapan sekolah dalam melaksanakan pembelajaran daring dilakukan oleh Waryanto dan Insani (2013) yang memperoleh hasil SMA Kota Yogyakarta telah masuk dalam kategori siap untuk melaksanakan pembelajaran daring selama masa pandemi covid -19 .

Untuk itu dibutuhkan persiapan yang matang dalam melaksanakan pembelajaran daring tersebut. Tidak hanya dari sarana prasarana tetapi juga dari kemampuan mahasiswa dalam menggunakan berbagai platform pembelajaran daring yang inovatif serta kesiapan mahasiswa dalam menghadapi kendala yang akan terjadi dalam pembelajaran daring. Informasi yang diperoleh dari penelitian ini nantinya diharapkan dapat memperbaiki ataupun mempersiapkan kebijakan yang lebih baik dan sesuai dengan kondisi di lapangan. Analisis ini berfokus pada mahasiswa dengan tujuan mendapatkan informasi lebih jelas mengenai kesiapan mahasiswa melaksanakan pembelajaran daring, dengan mengetahui kesiapan 
mahasiswa diharapkan dosen serta pemangku kebijakan dapat menyusun strategi yang sesuai terkait pengembangan pembelajaran daring yang akan dilakukan pada masa pandemi covid -19 .

\section{Metode Penelitian}

Jenis penelitian ini adalah deskriptif kualitatif. Subjek penelitian yaitu 53 mahasiswa prodi PGSD FKIP Universitas Mataram dari semester 1. Teknik pengumpulan data berupa angket terbuka dan wawancara. Angket disebarkan kepada 53 mahasiswa untuk melihat respon yang berikan. Wawancara dilakukan via telepon dari perwakilan mahasiswa. Teknik analisis dalam penelitian ini yaitu Analysis Interactive Model (Miles dan Huberman, 2005) terdiri dari data collection (pengumpulan data), data reduction (reduksi data), data display (penyajian data), dan conclutions (penarikan kesimpulan).

\section{Hasil dan Pembahasan}

\section{Kesiapan Sarana dan Prasarana}

Salah satu faktor pendukung terlaksananya pembelajaran daring adalah sarana dan prasarana. Sarana dan prasarana disini dapat berupa laptop, handphone, paket / kuota internet dan berbagai platform pendukung pembelajaran daring. Sesuai dengan perrnyataan Sobron (2019), sarana dan prasarana yang memadai seperti kuota internet, komputer / laptop, layar proyektor, aplikasi, media atau platform pembelajaran daring menjadi sarana prasarana yang paling penting dalam pembelajaran daring agar informasi atau pengetahuan yang disampaikan dapat diterima dengan baik.

Hasil kuesioner dan wawancara menunjukkan bahwa sarana prasarana yang belum mereka siapkan secara optimal untuk pelaksanaan pembelajaran secara daring berturut - turut mulai dari kuota internet 66,7\%, Laptop 28,4\%, Platform pembelajaran daring 3,7\%, dan handphone 1,2\%. Berikut merupakan grafik kesiapan sarana dan prasarana pembelajaran daring. 


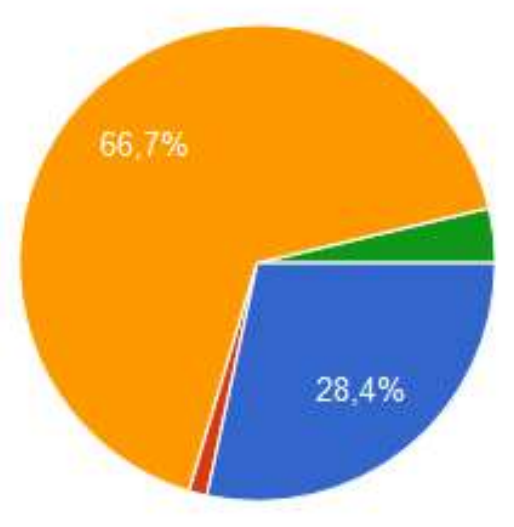

Grafik 1. Kesiapan Sarana dan Prasarana

Sumber: dokumentasi pribadi

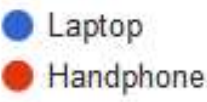

Paket / kuota Internet

Platform pembelajaran daring (Zoom, google meet, webex)

\section{Kesiapan Penggunaan Media / Platform Pembelajaran Daring}

Faktor selanjutnya yang tak kalah penting dalam pelaksanaan pembelajaran daring yaitu kemampuan penggunaan media / platform pembelajaran daring. Untuk memfasilitasi terlaksananya pembelajaran yang nyata dan optimal diperlukan platform yang dapat memfasilitasi dan sesuai dengan tujuan pembelajaran. Terdapat beragam jenis platform pembelajaran daring yang dapat digunakan untuk memfasilitasi kegiatan pembelajaran tersebut, diantaranya zoom, googleclass, whatsapp, daring unram, dan lainnya. Hasil penelitian menunjukkan bahwa sebagian besar mahasiswa cukup terbiasa dan dapat menggunakan berbagai platform pembelajaran daring tersebut (49,4\%).

Pembelajaran daring dapat dilakukan secara inovatif pada masa pandemi Covid-19 dengan memanfaatkan berbagai platform yang berimprovisasi dengan teknologi. Kelebihan pembelajaran daring dengan platform tersebut yaitu mampu memfasilitasi pembelajaran dengan berbagai metode yang interaktif selayaknya pembelajaran luring. Sehingga kemampuan penggunaan platform pembelajaran daring tersebut menjadi sangat penting dalam terlaksananya pembelajaran daring yang optimal (Almarzooq et al.,2020). 


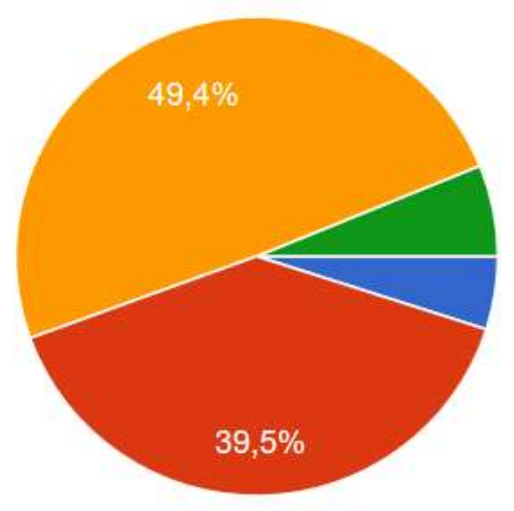

Sangat terbiasa

Terbiasa

Cukup terbiasa

Tidak terbiasa

Grafik 2. Kesiapan Penggunaan Media Pembelajaran Daring

Sumber: dokumentasi pribadi

\section{Kesiapan Menghadapi Kendala Pelaksanaan Pembelajaran Daring}

Dalam setiap kegiatan yang akan dilaksanakan tentunya akan menghadapi berbagai kendala, begitu pula pada kegiatan pembelajaran daring. Kesiapan peserta didik dalam menghadapi berbagai kendala yang akan muncul dalam pembelajaran daring merupakan hal yang penting dalam keberhasilannya mengikuti kegiatan pembelajaran. Peserta didik dituntut harus berperan aktif dalam setiap kegiatan pembelajaran dan mampu mencari solusi berbagai permasalahan yang akan dihadapi dalam pelaksanaan pembelajaran daring tersebut. Peserta didik harus mampu mengembangkan ide-ide inovatif dan solutif untuk mengatasi permasalahannya karena pada saat pelaksanaan pembelajaran daring guru tidak dapat secara langsung ikut membantu mencari solusi bagi tiap masalah yang akan dihadapi peserta didik tersebut (Alwiyah dan Imaniyati, 2018).

Mahasiswa diharapkan dapat mengidentifikasi kendala apa saja yang akan mereka hadapi dalam pelaksanaan pembelajaran daring kemudian mencari solusi untuk memecahkan masalah tersebut sehingga pembelajaran daring yang akan dilakukan nantinya dapat terlaksana secara optimal. Dari beragam permasalahan yang mungkin akan dihadapi oleh mahasiswa dalam pelaksanaan pembelajaran daring, permasalahan yang paling banyak muncul yaitu jaringan internet yang tidak stabil (88,9\%). Hasil wawancara menunjukkan bahwa, antisipasi mahasiswa dalam 
menghadapi kendala tersebut adalah dengan mencari lokasi yang memiliki jaringan yang stabil dan menyiapkan kuota internet dari berbagai provider sebagai back up. Solusi ini dinilai cukup solutif dan mampu menyelesaikan permasalahan tersebut.
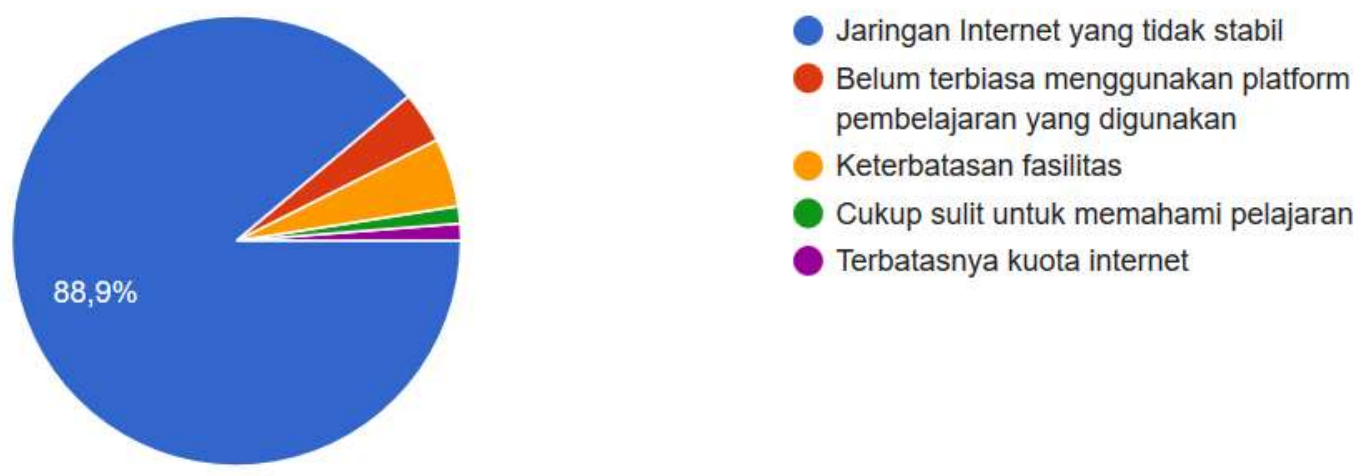

Grafik 3. Mitigasi Kendala Pelaksanaan Pembelajaran Daring Sumber: dokumentasi pribadi

\section{Kesimpulan}

Hasil penelitian menunjukkan bahwa sebagian besar mahasiswa PGSD semester 1 sudah siap menghadapi pembelajaran daring. Ditinjau dari kesiapan sarana prasarana. kesiapan dalam penggunaan media / platform pembelajaran daring, dan kesiapan dalam menghadapi kendala yang akan muncul pada saat pembelajaran daring berlangsung

\section{Daftar Pustaka}

Almarzooq, Z. I., Lopes, M., \& Kochar, A. 2020. Virtual Learning During the COVID-19 Pandemic. Journal of the American College of Cardiology. 75(20), 2635-2638.

Alwiyah, D., \& Imaniyati, N. 2018. Keterampilan Mengajar Guru dan Kesiapan Belajar Siswa sebagai Determinan Terhadap Hasil Belajar Siswa. Jurnal MANAJERIAL, 17(1), 95.

Aydin, C. H., \& Tasci, D. (2005). Measuring readinesss for e-learning: Reflection from emerging country. Educational Technology and Society Journal, 8(4), 244-257.https://www.learntechlib.org/p/75035

Bilfaqih, Y., \& Qomarudin, M. N. 2015. Esensi Pengembangan Pembalajaran Daring. Yogyakarta : E Publish.

Faslah, R., \& Santoso, H. B. 2017. Analisis kesiapan implementasi e-learning 
menggunakan e-learning readiness model. POSITIF : Jurnal Sistem Dan Teknologi Informasi, 3(2), 113. https://doi.org/10.31961/positif.v3i2.431.

Ghirardini, B. 2011. E-learning Methodologies. Germany: Federal Ministry of Food, Agriculture and Consumer Protection.

Miles, M., \& Huberman, M. 2005. No Qualitative Data Analysis. Jakarta : UI Press.

Nakayama M, Yamamoto H, \& S. R. . 2007. The Impact of Learner Characterics on Learning Performance in Hybrid Courses among Japanese Students. Elektronic Journal E-Learning, Vol.5(3).1

Nichols, M., \& McLachlan, C. 2006. E-learning and early childhood teacher education: what does the future hold? . He Kupu (The Word). Issue 1(1), $17-28$.

Setiaji, Bayu \& Dinata, Cahya Ariadi P. 2020. Analisis Kesiapan Mahasiswa Jurusan Pendidikan Fisika Menggunakan E-Learning dalam Situasi Pandemi Covid-19. Jurnal Inovasi Pendidikan IPA6 (1) 2020, 59-70.

Sobron, Bayu, Rani, \& Suswandari, M. 2019. Pengaruh Daring Learning terhadap Hasil Belajar IPA Siswa Sekolah Dasar. Seminar Nasional Sains Dan Entrepreneurship VI, 1(1), 1-5.

Waryanto, N. H., \& Insani, N. 2013. Tingkat kesiapan (readiness) implementasi elearning di sekolah menengah atas Kota Yogyakarta. Jurnal Pendidikan Matematika Dan Sains, 1(2), 117-124. 